\title{
AUTONOMY AND MOTIVATION: A SELF-DETERMINATION THEORY PERSPECTIVE ON ESP MOTIVATION
}

\author{
Ivana Rubić, Dora Matijević \\ University of Applied Sciences Velika Gorica, Velika Gorica, Croatia \\ E-mail: rubic.ivana@gmail.com
}

\begin{abstract}
Motivation is considered one of the central elements contributing to the success of language learning. It has been found that teachers' motivating style has substantive impact on student learning motivation and academic achievement. Hence, in the recent research, much attention has been devoted to conceptualization of motivation and identifying factors affecting learning motivation, as well as ways in which teachers may best develop students' motivational capacity. ESP students are commonly extrinsically motivated and extrinsic motivation is often associated with lower quality performance. Self-determination theory (SDT) offers a broadened conceptualization of extrinsic motivation, suggesting that in an environment responsive to students' psychological needs it represents a valuable resource which fosters high-quality learning. Such developments in the research on motivation have prompted a shift in approach to language learning motivation. Drawing from SDT, this paper aims to describe how certain aspects of the learning environment may support as well as undermine ESP motivation, and to provide direction for effective ESP classroom practice.
\end{abstract}

Key words: $S D T, E S P$, motivation, autonomy

\section{INTRODUCTION}

In recent years, a body of research explored the relationships between learners' psychological processes and motivational orientations, and has significantly contributed to a discussion on factors affecting student motivation to learn, either positively and negatively. Due to its complexity, the concept of motivation has been conceptualized differently by many theories which aimed to explain motivated action. However, in psychology, motivation is generally defined as the driving force behind all behavior. The complexity of motivation can be more appreciated if one takes into consideration that it is "intended to explain nothing less than the reasons for human behavior" (Dörnyei, Csizér, \& Németh, 2006 , p. 9). Furthermore, recent theoretical perspectives on learning motivation bring an important conceptual shift to understanding motivation as they recognize its dynamic and multi-dimensional nature being affected by contextual and individual processes. These developments have prompted a shift in approach to language teaching. In this paper, learning motivation is viewed within the framework of self-determination theory (SDT; Deci \& Ryan, 1985) which expands upon the widely acknowledged distinction between intrinsic and extrinsic motivation and views the concept of motivation on a continuum between autonomous and controlled forms of motivation. According to SDT, human nature 
is inherently active, assimilative and dynamic and it thrives under the conditions that support the satisfaction of innate psychological needs of autonomy, competence and relatedness but also becomes defensive, reactive and compliant under conditions of need deprivations and thwarts (Deci \& Ryan, 2012, p. 7). These three innate psychological needs are defined in terms of psychological processes as nutrients that are essential for highquality motivation, human development and well-being. Satisfaction of the needs of autonomy, competence and relatedness directs how people feel and behave. Accordingly, when one's inner psychological needs are satisfied by the individual's social milieu, the individual becomes more motivated to act and shows greater positive outcomes in the educational setting (Deci \& Ryan, 1985, 2002).

In the language education research, the interest in the concept of autonomy has been growing even though it has often been approached differently than in SDT. In language education autonomy is a concept which mostly focuses on developing students' ability to learn by themselves and for themselves, i.e. the ability to make independent and responsible decisions about their own learning. However, drawing on SDT and other theories in educational psychology, several authors have explored the relationships between motivation, autonomy and self-processes of the learner (Dornyei, 2001, 2011; Noels, 2001; Ushioda, 1996, 2008). This represents a considerable shift from the earlier research which regarded autonomy only as an important characteristic of a good learner. Ushioda (2008) presented an alternative view of motivation noting that "motivation has traditionally been regarded as something that teachers "do" or "give" to learners through a variety of motivational tricks and strategies, whereas current insights emphasize the importance of fostering learners' own motivation and sense of self-determination" (p. 28). According to Dornyei (2001) teachers' motivational skills are central to teaching effectiveness. However, teachers should aim to become 'good enough' motivators rather than 'supermotivators', striving for quality rather than quantity and creating a positive motivational learning environment (Dornyei, 2001, p. 116).

Due to the dominance of English as a 'global language' in business, science and technology, the field of English for Specific Purposes (ESP) has been developing rapidly. A distinguishing characteristic of ESP is that it is designed to meet specified needs of the learner. Given its pragmatic purpose, ESP entails a rather strong instrumental view of language learning. Consequently, ESP learning motivation is commonly viewed very narrowly as being only or mostly about perceived relevance for students' future career without sufficient attention being given to other important factors which may nurture students' motivation for extrinsically valued goals. Namely, ESP practitioners often report that students' motivation and effort to engage with language learning are difficult to sustain despite students' increasing wish to improve the proficiency of the target language. According to Ryan and Deci (1985), founders of SDT, extrinsic motivation, as well as intrinsic, may foster high-quality learning, if a person's psychological needs are satisfied.

This article argues that sustaining high levels of student motivation requires consistent teacher effort, even with students with high abilities, and that teacher behavior may nurture as well as undermine student motivation for learning. Drawing from selfdetermination theory, this paper aims to offer insight and guidance on how to increase the motivational quality of the ESP learning environment by strengthening students' sense of personal satisfaction in learning. 


\section{SELF-DETERMINATION THEORY OF MOTIVATION}

Self-determination theory is a macro-theory of motivation which examines how interactions between a person's internal processes and social-contextual factors affect a persons' motivation and behavior. It was introduced by Deci and Ryan (1985) as an elaboration of the intrinsic/extrinsic paradigm (Dörnyei, 1998) and focuses not only on the level but also on different types, i.e. qualities of motivation. Autonomy, or self-determination, is a fundamental theoretical principle in SDT. According to SDT, autonomy is a form of volitional functioning that is affected by satisfaction of psychological needs and the socialcontextual factors. Central to self-determination theory (SDT) is the belief that the satisfaction of the three basic psychological needs of autonomy, competence, and relatedness in the social context enhances the natural processes of autonomous motivation and, consequently, fosters high-quality learning. According to STD people have an innate need to be autonomous. The need for autonomy is of central importance for human development and well-being and refers to individuals' need to behave with a sense of volition, willingness, and congruence as one aspires to fully endorse and concur with the behavior one is engaged in (Deci \& Ryan, 2012). Thus, to be autonomous or self-determined is not so much about being free from external factors but it refers to experiencing autonomy through internalizing the value and significance of certain behavior. In addition to the need for autonomy, people have a need of competence and a need of relatedness. When these three needs are supported in the classroom, students are more likely to internally value academic goals and tasks which increases high-quality motivation and voluntarily engagement. Accordingly, the quality of student motivation depends on the degree to which the teacher is able to meet students' needs of autonomy, competence, and relatedness. Regarding types of motivation, SDT distinguishes between a lack of motivation referred to as amotivation, and different types of motivation depending on the degree of self-determination i.e. autonomy (Figure 1).

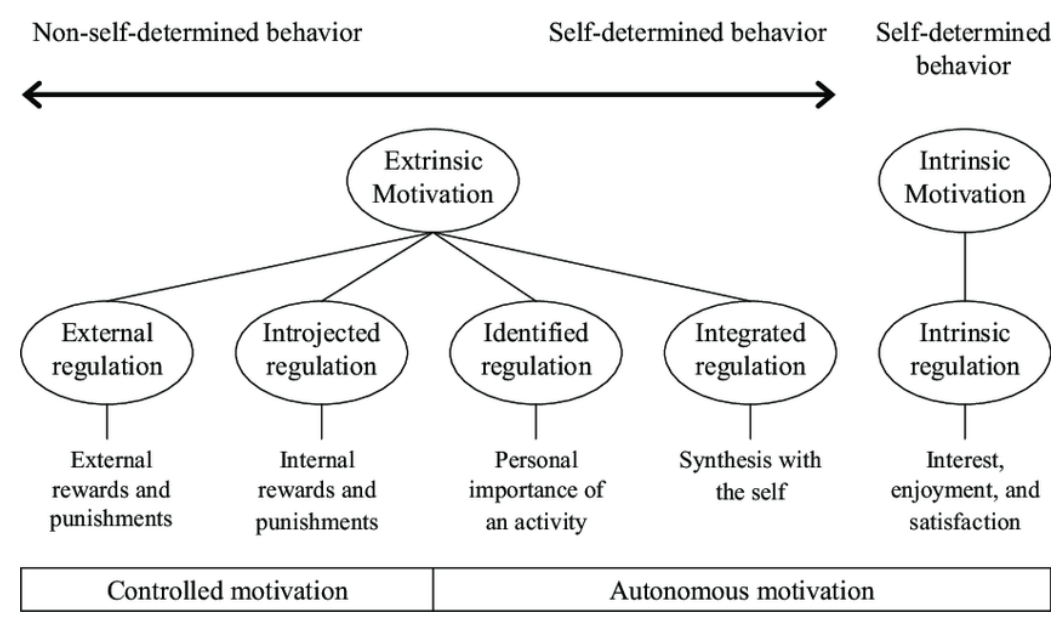

Fig. 1 Ryan and Deci's types of motivation

Source: van Beek, Ilona, Toon, W. Taris, and Wilmar B. Schaufeli 2011.

Intrinsic motivation is the most autonomous, and as such the most effective type of motivation and refers to doing something because it is inherently interesting or enjoyable, and 
"extrinsic motivation refers to doing something because it leads to a separable outcome" (Ryan \& Deci, 2000, p. 55). However, this theory broadens a narrow understanding of extrinsic motivation by classifying it into four types, or qualities, depending on the degree of autonomy or self-determination. The most autonomous type of extrinsic motivation referred to as integrated regulation is regarded as a highly effective type of motivation and it approximates intrinsic motivation in its degree of self-determination (autonomy). However, integrated regulation is still extrinsic as it is based on the importance of the activity, "whereas intrinsic motivation is based on interest in the activity and emerges spontaneously" (Reeve, 2012, p. 155). In that respect, it is the social and environmental factors which may elicit, sustain, and enhance autonomous motivation whereas others may subdue or diminish it (Deci \& Ryan, 1985).

Self-determination theory puts a strong focus on the educational context by giving guidance on how students' extrinsic motivation for learning can be regulated so it is more internalized, meaning that driven behavior is perceived as coming from the self rather than from external source. For instance, when students are faced with a task that they do not perceive as interesting and enjoyable they may avoid engagement if not internally motivated. As opposed to externally motivated students, those internally motivated learn out of curiosity and authentic interest and find the reward in learning itself. The proposition that the social-contextual factors may facilitate internalization of learning goals and values and thus regulate extrinsic motivation has important pedagogical implications for classroom practice. Namely, teachers' autonomy supportive behavior creates a strong motivational impact on students and enables students to experience engagement in learning as valuable and useful for themselves. Deci and Ryan $(1985,2002)$ point to the benefits of autonomysupportive learning environment in fostering quality motivation, whereas controlling environment undermines its development. By creating autonomy-supportive conditions teachers facilitate student engagement which is wholly volitional as it is associated with internal satisfaction. By contrast, in a controlling learning environment quality motivation is undermined and student behavior is accompanied by a sense of negative pressure. Hence, if a student identifies with the importance of studying or engaging in a task, he will then engage willingly whether or not he is monitored or feels external pressure.

In an autonomy-supportive learning environment, a teacher considers learning from a learners' perspective and works to strengthen teacher-student relationships by e.g. providing meaningful rationales to students, plenty of choices and regular positive feedback about students' learning process. What makes a learning environment more autonomy-supportive in terms of satisfying students' needs of competence, autonomy and relatedness, as well as pedagogical implications, will be discussed further in the paper.

\subsection{Autonomy and competence}

The significance of competence as a self-concept has been established in various motivation theories and thus deserves serious attention. Previous research has shown that self-perceived competence affects students' motivation and engagement (Bandura, 1997; Deci and Ryan, 2002; Dornyei, 2001; Niemiec and Ryan, 2009; Ushioda, 2011). Selfefficacy is the central concept of Bandura's social cognitive theory (1997) and is defined as "people's beliefs about their capabilities to produce designated levels of performance which determines how they feel, think, motivate themselves, and behave" (Bandura, 1994, v.4, p. 71). According to Bandura the most effective way of developing high self-efficacy beliefs 
in students is through mastery experiences. To that purpose, teachers are encouraged to provide plenty of opportunities for students to experience success in learning by using strategies such as guidance, scaffolding instruction, reflection (Little, 1995; Meddings \& Thornbury, 2009) which help students persist in difficult tasks. Having a direct experience of mastery is especially important with students who have a low sense of self-perceived competence as it builds students' confidence and it gives them confirmation that invested effort will return.

SDT suggests that autonomous types of motivation are enhanced when students feel competent, related, and autonomous. Also, teachers' understanding of what self-beliefs are and how they are developed is an important requirement for long-term teaching effectiveness. It is central that students can actually understand and master the learning activities so that their sense of competence can be developed (Niemiec and Ryan, 2009). In SDT, competence is an inherent psychological need of humans, which is conceptually similar to Bandura's concept of self-efficacy and it is defined as "the need to be effective in one's pursuits and interactions with the environment" (Reeve, 2012, p. 154). Even if students have high abilities but do not perceive themselves as academically competent and productive, they may not persist in learning or achieve their full academic potential. If in self-doubt, students may complain about some aspect of their learning experience e.g. workload, assignments, assessment or may avoid engagement instead of making greater effort to persist. Amotivation, for instance, might be the result of not feeling competent to perform a task (Deci, 1975).

According to SDT, teacher support for the need of competence includes adjusting goals according to students' ability to make sure students feel comfortable enough to use their knowledge and engage in learning activities. Ideally, learning goals should not be too high so that students can achieve them but still should be challenging enough to spark students' interest and curiosity. Furthermore, teachers should provide students with clear and timely information about their progress and ways to improve it, which encourages them to reflect on their learning and invest further effort.

Building students' sense of competence is a challenging but important component of teaching strategies as it encourages students to set higher goals for themselves and perform better academically. However, SDT suggests that a support of autonomy and competence alone will not suffice to enhance the autonomous types of motivation unless accompanied by a sense of relatedness.

\subsection{Autonomy and relatedness}

Following the self-determination theory, to strengthen students' sense of personal satisfaction in learning the support of all three basic needs is required in a learning environment. Relatedness as the third basic psychological need is centrally important for autonomy-support and internalization of goals and values (Deci and Ryan, 2000), and it refers to a feeling of belonging and connection with others. "In the classroom, relatedness is deeply associated with students' feeling that the teacher genuinely respects and values them" (Niemiec \& Ryan, 2009, p. 139). In that regard, teaching strategies that support relatedness are those which strengthen the relationships between the teacher and learners, as well as among learners, and entail emotional support and respect. When teachers express understanding for students' learning experiences, especially the difficulties and discomforts, students' need for relatedness is supported. On the other hand, controlling teacher behavior, contributes to students feeling pressured and disconnected. 
According to SDT, teachers should actively listen to students and provide them with opportunities to make decisions and choices regarding their learning. Also, it is important to provide meaningful rationales to students so that they understand the benefits and the relevance of tasks and activities. In the view of the foregoing, such student-centered practices give students a sense of ownership and volition and thus support autonomy in learning.

\section{AUTONOMY AND MOTIVATION IN LANGUAGE EDUCATION}

In this paper, the parallel between SDT and foreign language education is observed in placing the focus on the learner, namely through the promotion of autonomy, learnercentered instruction, authenticity and positive human relationships. In the language education field autonomy has long been regarded as an important pedagogical principle associated with many positive educational outcomes, academic and social and, more recently, motivational. Since Holec (1981) first proposed the definition of learner autonomy, the interest in research on autonomy has grown and different theoretical perspectives have emerged. Holec (1981) defined learner autonomy as "the ability to take charge of one's own learning" (p. 3) referring to the potential capacity of students to think and act independently. Dickinson (1987) looked at autonomy as a learning situation "in which the learner is totally responsible for all of the decisions concerned with his learning and the implementation of those decisions" (p.11). Taking responsibility for one's own learning commonly refers to being involved in making independent and responsible decisions with regard to setting one's goals, use of learning strategies, ways of monitoring one's own progress, and self-expression. Hence, the concept of autonomy in language education has mostly been linked with applying teaching strategies to encourage learners to become active and responsible contributors to their learning. Autonomous learning techniques have been regarded as additional learning skills that students need to acquire over time through practice to become more effective learners.

However, in the recent years, several researchers have further advanced the conceptualization of autonomy by looking at the relationships between autonomy, selfprocesses, agency and motivation. According to Dam (2011), autonomous learning includes two components, willingness and capability, which a student needs to take charge of. Consequently, teachers' responsibility is to make learners willing to take over the responsibility for their own learning and support students in becoming capable of doing so (Dam, 2011). Littlewood (1996) expressed a similar view on autonomy and defined it as both learners' ability and willingness to make choices independently. The ability refers to both knowledge and skills as necessary requirements for making choices and decisions, and willingness refers to "motivation and the confidence to take responsibility" for one's decisions (Littlewood, 1996, p. 428). Nunan (1997) proposed there are degrees of autonomy that a learner can achieve in a learning environment and suggested a nine-step procedure for helping students to progress along the continuum from dependence to autonomy. Sinclair (2000) contributed to a deeper understanding of autonomy by highlighting 13 aspects of learner autonomy which have been acknowledged in language education (Table 1). 
Table 1 Aspects of learning autonomy (Sinclair, 2000)

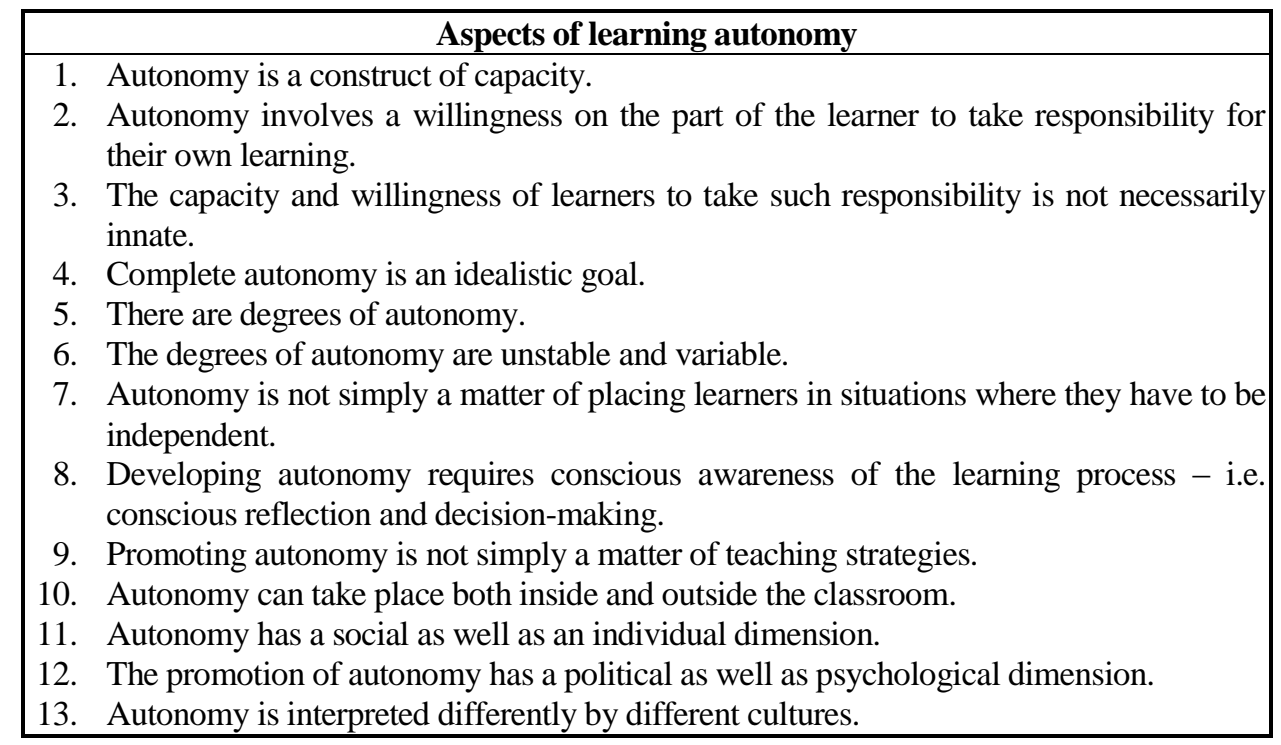

Benson (1997) and Oxford (2003) proposed a more comprehensive framework of learner autonomy which should be constructed by taking into consideration a whole range of different perspectives and aspects. Benson (1997) introduced four versions, or ways, of representing the idea of autonomy; 'technical' version related to learning management, 'psychological' version related to attitudes and cognitive processes, 'political' version related to giving learners' control of learning process, and 'sociocultural' version related to the role of social interaction in the development of learner autonomy (Oxford, 2003). In each of these aspects of autonomy learners may progress from 'lower' to 'higher' levels. Benson (2008) also notes that in language learning, the perspective which focuses on a teachers' role in the development of autonomy as a learning skill takes dominance at the expense of the perspective that focuses on learner's personal autonomy. Benson (2008) is critical of such a narrow idea of autonomy in learning, and stresses that "Personal autonomy entails learner autonomy, because the process of learning to be autonomous must itself involve autonomy" (p. 37).

Further, autonomy in language learning (LL) has recently been considered as a process that greatly impacts motivation. Much LL research, some of which has been based on the concepts from self-determination theory (Deci \& Ryan, 1985; Ryan \& Deci, 2000), has focused on the relationships between autonomy, identity and motivation emphasizing the relevance of teacher motivating style and learner self-processes for the learning effectiveness. It is clear that motivation, which has been regarded as a central factor responsible for student success in learning is no longer seen as a unitary stabile process but rather as a complex and dynamic phenomenon, which is affected by the interactions between learner's individual characteristics and the aspects of the learning environment. Ushioda $(2006,2011)$ and Dornyei (2011) pointed to the importance of motivation that comes 'from within' and the ways of helping students think positively and constructively and thus shape their own motivation. Also, Ushioda (2011) noted that 
some LL classroom practices somewhat preceded motivation theory as “...engaging our students' identities is something that many experienced language teachers have intuitively recognized as important, and is a principle that has often found its way into the language teacher training literature in the shape of buzzwords like learner-centered teaching, authentic communication, personalization and so on. (p. 17)"

Drawing on self-determination theory, Noels (2001) investigated how autonomysupportive teaching (versus controlling), as conceptualized by SDT, affects the language learning process. She found that autonomy-supportive teacher behaviour is correlated with positive students' perceptions of their autonomy and competence, and associated it with stronger endorsement of internalized or intrinsic reasons for learning the language. Further, Dornyei (2011) investigated what makes a classroom environment motivating and introduced a L2 Motivational Self-System arguing that one's vision of successful possible self is a powerful motivational tool. When addressing the question of LL motivation, Dornyei (1994) suggested that teachers should "Promote learner autonomy by allowing real choices about alternative ways to goal attainment; minimising external pressure and control (e.g., threats, punishments); sharing responsibility with the students for organising their time, effort and the learning process; inviting them to design and prepare activities themselves and promoting peer-teaching; including project work where students are in charge; and giving students positions of genuine authority. (p. 282)"

In the light of the foregoing, it can be inferred that SDT perspective is relevant to language learning as it provides a wider motivational context and additional reasoning on 'the Why' of autonomy in language learning and thus complements a more traditional perspective on autonomy acknowledged in the language education field. Many principles which SDT promotes have been generally accepted in LL teaching, such as feedback, emotional support, autonomy in learning, but having knowledge of those principles without understanding why it is the case may result in a gap between teachers' intentions and the result of their practices. Establishing the balance in addressing students' academic and non-academic needs requires deeper understanding of motivational teaching and its theoretical foundations. Also, conceptual and theoretical clarity instigates teachers to develop their conceptions of teaching, as well as of student needs, and to recognize those needs as students' strengths, not barriers, which can be developed to benefit student learning.

\section{SELF-DETERMINATION THEORY IN THE CONTEXT OF ESP MOTIVATION}

As the demand for ESP courses is growing, this field of language teaching is developing rapidly. Although ESP practitioners have proven to be open to innovation and possibilities in the classroom, additional understanding of learners' psychological factors and adding more context information to the new and existing teaching practices may increase teachers' motivational impact. Designed to meet specific learners' needs, ESP courses are often thought to be meaningful and motivating enough in itself. However, sustaining academic motivation requires a consistent teacher effort to better identify and meet learners' wants and needs. Although ESP is a relatively new branch within language teaching, ESP teaching has undergone significant changes over the last several decades which has greatly improved the effectiveness of ESP courses. Given the specificities that shape its course design, ESP is today regarded as needs-based/learner-centered approach 
to language learning (Hutchinson \& Waters, 1987; Belcher, 2004) and hence requires needs-knowledgeable instructors (Belcher, 2009). As Belcher (2004) put it "Unlike other pedagogical approaches, which may be less specific-needs-based and more theory-driven, ESP pedagogy places heavy demands on its practitioners to collect empirical needs assessment data, to create or adapt materials to meet the specific needs identified, and to cope with often unfamiliar subject matter and even language use. (p. 166)"

Needs analysis have long been regarded as fundamental prerequisite for effective ESP course design (Robinson, 1991). Approaches to needs analysis depend on practitioner's objectives but mostly aim to identify the target language and target skills learners need to master to successfully meet the demands of specific situations. However, Belcher (2017) highlights the importance of taking a critical, multi-perspective approach to needs with a focus on fostering students' autonomy and agency as language learners and community participants. Such approach to needs analysis should greatly improve the effectiveness of language learning.

In addition, as student effort and success in learning is conditioned by their motivational state, which has been found to fluctuate over time, it is essential for teachers to understand how specific individual and contextual factors impact students' attitudes and learning motivation. Ushioda (2011) looks at the dynamic relationships between motivation, autonomy and identity and stresses that in educational psychology "motivation is not necessarily regarded as achievement-oriented but value-based and identity-oriented" ( $\mathrm{p}$. 221). She argues that language learners "are uniquely complex individual 'people' with particular social identities, situated in particular contexts" (Ushioda, 2011, p. 222) and should be approached as such.

According to SDT, autonomy-supportive environments conform to students' needs and personal values and as such facilitate authentic motivation and student engagement. SDT framework contributes to teachers' knowledge and understanding of non-academic needs which, when satisfied, keep students motivated for intrinsically and extrinsically valued goals and tasks. With regard to these theoretical considerations it may be inferred that a range of concepts promoted by SDT such as academic and emotional support, purposefulness, autonomy, authenticity and learner agency have had considerable relevance to language learning education in general and especially to ESP. However, the operationalization of these principles in the classroom with a view to support of motivational processes poses many challenges for practitioners.

The question of authenticity in learning has been discussed in ESP regarding the importance of authentic materials and learning activities. The value of using authentic materials is mostly recognized, however, it is even more important to successfully use authentic materials in the classroom. Dudley Evans and St. Johns (1998) noted that "Exercises that ask students to answer comprehension questions by finding relevant sentences in the text are not authentic, but those that ask students to use information from the text in a task or problem-solving activity are" (p. 28).

Further, the nature, amount and quality of communication in the classroom directly affects the language learning process. In a language classroom, giving students a voice in the classroom and inviting them to self-express is commonly promoted so as to facilitate authentic language use. However, it is not easy to have all students participate voluntarily in structured oral activities due to speech anxiety, fear of negative evaluation or lack of self-confidence or motivation. Namely, students' perceptions of classroom communication and learning environment directly affect their self-beliefs concerning their competence 
and how much they like and value learning, and thus affect the effectiveness of language courses. On that account, keeping balance between autonomy and authority has commonly been regarded as central to ESP teaching as it helps students overcome the fear of making mistakes and a sense of discomfort. In addition, inviting learners to engage voluntarily in organized learning and convey ideas entails a responsibility for teachers to ensure both emotional support and constructive feedback in order to maintain students' interest and effort in learning.

Next, building quality teacher-student relationships and supportive learning climate are considered as vital in both SDT and ESP. Although good teaching is often motivating in itself, learners are often unaware of challenges that language learning entails which can leave them feeling frustrated and disappointed with the course and themselves. This is why, the effective support of affective and motivational processes is vital to learning effectiveness, and given the complex nature of motivation, a collaborative effort between disciplines is required. Challenging as it is, motivation is best addressed by building on contributions of several theories as there is no single theory that can serve to encompass and clarify all the factors. SDT perspective on learning motivation provides a deeper understanding of ways of capitalizing on students' inner motivational resources and thus contributes to closing the gap between teachers' professional knowledge and actual classroom practices. In that regard, SDT contributes to optimization of learning conditions by determining underlying reasons which might be behind students' actions, perceptions and attitudes, and sheds a new light on the appropriateness of particular teaching practices.

\section{CONCLUSION}

Designed to meet specific learners' needs ESP courses are often thought to be meaningful and motivating enough in itself. Due to such narrow understanding of ESP motivation, teachers often feel that they lack additional tools to keep students interested and engaged. Instrumental types of aims in ESP are justified, but purely instrumental approach to the language learning undermines learning motivation and impedes the learning process. As ESP courses are often based on the need of the learner to use English as a tool for professional advancement, ESP students are commonly extrinsically motivated. Extrinsic motivation is often viewed as purely instrumental and less favorable type of motivation, and is as such often associated with negative students' attitudes toward learning, such as disinterest and resentment. SDT opens a different perspective on the quality of extrinsic motivation suggesting that the support of needs of autonomy, competence and relevance helps students internalize external motivational factors which makes a learning experience more interesting and satisfying.

In addition, part of what makes sustaining ESP motivation complex is that there are differences existing among ESP students in terms of social and educational background, language proficiency, age, etc. Thereby, contribution of SDT lies in specifying valuable inner sources of learning motivation, as well as demotivation, which students may not even be aware of. Knowledge of the factors that contribute to learner's motivation gives teachers direction for the use of motivational strategies and helps them to better understand students' needs and to recognize them as students' potentials which should be developed, not weaknesses. In that regard, SDT offers important insights on how to structure a learning environment to function as a multiple support system in which students construct knowledge volitionally, actively and purposefully. 


\section{REFERENCES}

Bandura, Albert. "Self-efficacy." In Encyclopedia of Human Behavior (Vol. 4, pp. 71-81), edited by V. S. Ramachaudran. New York: Academic Press, 1994. (Reprinted in H. Friedman [Ed.], Encyclopedia of mental health. San Diego: Academic Press, 1998).

Bandura, Albert. Self-efficacy: The exercise of control. New York: Freeman, 1997.

Belcher, Diane D. "Trends in teaching English for specific purposes". Annual Review of Applied Linguistics, 2004, 24(1):165-186.

Belcher, Diane D. "What ESP is and can be: An introduction." In English for Specifc Purposes in Theory and Practice, edited by D. Belcher. Ann Arbor, M.I.; University of Michigan Press, 2009b.

Belcher, Diane D. "Recent Developments in English for Specific Purposes." In Synergies of English for Specific Purposes and Language Learning Technologies. Cambridge Scholar Publishing, 2017: 2 - 19.

Benson, Philip and Peter Voller, eds., Autonomy and Independence in Language Learning. London: Longman, 1997.

Benson, Philip. “Autonomy in language teaching and learning." Language Teaching, 2007, < https://doi.org/10.1017/S0261444806003958 > (10 January 2019).

Benson, Philip. "Autonomy in language learning, learning and life." Synergies France, 9, 2012: 29-39.

Boo, Z., Zoltán Dörnyei, and Stephen Ryan. "L2 motivation research 2005-2014: Understanding a publication surge and a changing landscape.” System, 2015, 55: 145-157.

Deci, Edward L. Intrinsic motivation. New York: Plenum, 1975.

Deci, Edward L., and Richard M. Ryan. Intrinsic Motivation and Self-determination in

Human Behavior. New York, NY: Plenum Press, 1985.

Deci, Edward L., and Richard M. Ryan. Handbook of Self-determination Research. Rochester: The University of Rochester Press, 2002.

Deci, Edward L., and Richard M. Ryan. "Motivation, Personality, and Development Within Embedded Social Contexts: An Overview of Self-Determination Theory." In The Oxford Handbook of Human Motivation, edited by Richard M. Ryan. Oxford University Press, New York, 2012: 85-107.

Dickinson, L. Self-instruction in Language Learning. Cambridge: CUP, 1987.

Dörnyei, Zoltán. "Motivation and motivating in the foreign language classroom." Modern Language Journal, 1994, 78(3): 273-284.

Dörnyei, Zoltán. "Motivation in second and foreign language learning." Language Teaching, 1998, < https://doi.org/10.1017/S026144480001315X > (7 December 2018).

Dörnyei, Zoltán. Motivational strategies in the language classroom. Cambridge:

Cambridge University Press, 2001.

Dörnyei, Zoltán, and Ema Ushioda. Teaching and Researching Motivation (2nd ed.). Harlow: Longman, 2011.

Dörnyei, Zoltán., Kata Csizér, and Nóra Németh. Motivation, language attitudes and globalization: A Hungarian perspective. Clevedon: Multilingual Matters, 2006.

Dudley-Evans, Tony, and Maggie-Jo St John. Developments in English for Specific Purposes: A Multi-Disciplinary Approach. Cambridge: Cambridge University Press, 1998.

Holec, Henri. Autonomy in Foreign Language Learning. Oxford: Pergamon, 1981.

Hutchison, Tom, and Alan Waters. English for specific purposes: A learning - centred approach. Cambridge: Cambridge University Press, 1987.

Little, David. "Learning as dialogue: The dependence of learner autonomy on teacher autonomy." System, 1995, 23(2): 175-181. 
Littlewood, William. “"Autonomy': An Anatomy and a Framework.” System, 1996, 24: 427-435.

Meddings, Luke, and Scott Thornbury. Teaching unplugged: Dogme in English language teaching. Peaslake: Delta Publishing, 2009.

Niemiec, Christopher P., and Richard M. Ryan. "Autonomy, competence, and relatedness in the classroom: Applying self-determination theory to educational practice." Theory and Research in Education, 2009, 7: 133-144.

Noels, Kimberly A. "Learning Spanish as a second language: Learners' orientations and perceptions of their teachers' communication style." Language Learning, 2001, 51: $107-144$.

Nunan, David. "Designing and adapting materials to encourage learner autonomy." In Autonomy and independence in language learning, 192-203, edited by P. Benson, and P. Voller. London: Longman, 1997.

Oxford, R. L. "Toward a more systematic model of L2 learner autonomy." In Learner autonomy across cultures: Language education perspectives, 75-91, edited by D. Palfreyman, and R. C. Smith. Basingstoke: Palgrave Macmillan, 2003.

Reeve, Johnmarshall. "A self-determination theory perspective on student engagement." In Handbook of research on student engagement, 149-173, edited by S.L. Christensen, A.L. Reschly, and C. Wylie. New York: Springer, 2012.

Robinson, Pauline. ESP Today: A Practitioner's Guide. Hemel Hempstead: Prentice Hall International, 1991.

Ryan, Richard M. The Oxford Handbook of Human Motivation. Oxford University Press, 2012.

Ryan, Richard M., and Edward L. Deci. "Intrinsic and Extrinsic Motivations: Classic Definitions and New Directions." Contemporary Educational Psychology, 2000, < http://dx.doi.org/10.1006/ceps.1999.1020 > (10 January, 2019).

Ryan, Richard M., and Edward L. Deci. Self-determination theory: Basic psychological needs in motivation, development, and wellness. New York: Guilford Press, 2017.

Sinclair, Barbara. "Learner autonomy: The next phase." In Learner autonomy, teacher autonomy: Future directions, $4-14$, edited by B. Sinclair, I. McGrath, and T. Lamb. London: Longman, 2000.

Ushioda, Ema. Learner autonomy 5: The role of motivation. Dublin, Ireland: Authentik, 1996.

Ushioda, Ema. "Motivation as a socially mediated process." In Learner Autonomy in the Foreign Language Classroom: Teacher, Learner, Curriculum and Assessment, 90-102, edited by D. Little, J. Ridley, and E. Ushioda. Dublin: Authentik, 2003.

Ushioda, Ema. "Motivation and good language learners." In Lessons from Good Language Learners, 19-34, edited by Carol Griffiths. Cambridge, U.K.: Cambridge University Press, 2008.

Ushioda, Ema. "Why autonomy? Insights from motivation theory and research." Innovation in Language Learning and Teaching, 2011, <http://dx.doi.org/10.1080/17501229. $2011.577536>$ (15 December 2018).

Ushioda, Ema. "Motivating learners to speak as themselves." In Identity, Motivation and Autonomy in Language Learning, 11-24, edited by G. Murray, X. Gao and T. Lamb. Bristol, U.K.: Multilingual Matters, 2011.

van Beek, Ilona, Toon, W. Taris, and Wilmar B. Schaufeli. "Workaholic and work engaged employees: Dead ringers or worlds apart?” Journal of Occupational Health Psychology, 2011, < http://dx.doi.org/10.1037/a0024392 > (11 January 2019). 